\title{
Charles Peirce's Limit Concept of Truth
}

\author{
Catherine Legg \\ University of Waikato
}

\begin{abstract}
This entry explores Charles Peirce's account of truth in terms of the end or 'limit' of inquiry. This account is distinct from - and arguably more objectivist than - views of truth found in other pragmatists such as James and Rorty. The roots of the account in mathematical concepts is explored, and it is defended from objections that it is: i) incoherent, ii) in its faith in convergence, too realist, and iii) in its 'internal realism', not realist enough.
\end{abstract}

Peirce famously wrote, "Inquiry properly carried on will reach some definite and fixed result or approximate indefinitely toward that limit" $(1.485)^{1}$ and, "The opinion which is fated to be ultimately agreed to by all who investigate, is what we mean by the truth" (5.407). These remarks, often glossed in the slogan: 'Truth is the end of inquiry', offer an understanding of truth which is arguably distinct from the usual suspects of correspondence, coherence, deflationary, and identity theories of truth (and providing an account of this philosophically fundamental notion that is so original is no mean feat). The understanding of truth is also very different from the instrumentalism of pragmatists such as James (in, for example, Pragmatism). This entry explores the extent to which Peirce can be said to present 'a limit concept of truth', locates the view within his pragmatism, explains how its teleological character renders it neither 'ontological' nor 'semantic' in the contemporary sense, explores its roots in a concept of limit that is strictly mathematical, and defends it from the objections that it is: incoherent (section 3), in its faith in convergence, too realist (§4) and in its 'internal realism', not realist enough (§5).

This is not intended to be an exhaustive overview of everything Peirce had to say on truth. It presents his understanding of truth very much from the perspective of analytic philosophy, in which considering language in relative isolation from other human activities and attempting to theorise its truth-conditions has been a significant preoccupation. There are other rich stories to be told about truth in Peirce's thought, including an evolutionary story in which what Peirce called "fixation of belief" is only guaranteed by communal inquiry which inevitably grows in

\footnotetext{
${ }^{1}$ All references to Peirce's writings in this entry are to his Collected Papers, stating the volume followed by the paragraph number.
} 
sophistication, a semiotic story regarding differing, mutually supportive roles for different kinds of signs (such as iconic, indexical and symbolic) in reaching the truth, and a story about how Peirce grounds truth in the normative sciences as the founding concept of logic understood as a species of ethics (since thought is a kind of action). But our chosen topic has a certain self-sufficient focus which it is hoped will be useful.

\section{The Meaning of Truth}

\subsection{The Mathematical Metaphor and Its Uses}

A literally mathematical understanding of the limit of a convergent series may be discerned in Peirce's remark, cited earlier:

Inquiry properly carried on will reach some definite and fixed result or approximate indefinitely toward that limit (1.485).

In deriving $\pi$ algorithmically we obtain a number which grows ever longer in decimal places and ever closer to $\pi$ itself. Likewise, truth for Peirce is defined as what we grow ever closer towards by inquiring. The mathematical formulation is no accident, since Peirce envisaged the sciences forming a hierarchy with mathematics at the top providing fundamental conceptions to sciences below. Peirce was a keen follower of $19^{\text {th }}$ century developments in the mathematical understanding of infinity. Key insights not without relevance here were the clarifications of Weierstrass (and others) of ways to make sense of a determinate value standing at the limit of an infinite process, and Cantor's profound discovery that countable infinity is 'not the greatest quantity', and not sufficient for continuity. The concept of continuity was extremely important to Peirce, who extended it into epistemology, metaphysics and other disciplines, and at one point described it as the "keystone to the arch" of his thinking (and himself as a synechist for that reason. See for instance: $6.103,6.169,6.202)$.

However the concept of truth only enters Peirce's scientific hierarchy in the discipline of logic, and it is important to understand the key role in its establishment played by Peirce's pragmatism. As has been well noted (Misak, Truth and the End of Inquiry, The New Pragmatists, Hookway, The Pragmatic Maxim), in describing truth as the limit of inquiry Peirce is not offering a new theory of truth so much as saying that this is what we mean by the truth. For Peirce, unlike James, pragmatism is not a theory of truth but merely a tool - in the form of the famous Pragmatic Maxim - for clarifying the meaning of difficult concepts.

The Pragmatic Maxim was presented in Peirce's famous early paper "How to Make Our Ideas Clear". Here he outlines three grades of clarity our concepts can attain. At the first grade we can 
identify a concept's instances without necessarily being able to say how. At the second grade we can give the concept a verbal or 'nominal' definition, as found in a dictionary. At the third grade we can derive future expectations from hypotheses containing that concept. Thus in Peirce's famous example, the first grade of clarity is to state, "This table is hard", the second grade is to state something like, "Hardness is the ability to resist pressure", and the third to predict, "If I rest my lunch on this table, it will not fall through".

In this framework the Correspondence Theory of Truth can be seen to lie at the second grade of clarity, since whatever 'lies behind' behind our true beliefs and 'corresponds' to them, is not examinable separately from them (otherwise epistemology would be an easier discipline). Peirce's explication of truth does not contradict the Correspondence Theory but goes further in providing expectations from the hypothesis that a statement is true - for instance, that further inquiry will not overturn it. (Misak, Truth and the End of Inquiry, The New Pragmatists 68-9). Forster argues that Peirce's account also does not quarrel with - but rather incorporates - the Coherence Theory of Truth, since Peirce understands logical inference as an inescapable tool of inquiry, and also Instrumentalist theories of truth insofar as inquiry arises in lived experience which is goal-directed (Peirce and the Threat of Nominalism 174-5).

Peirce's account also makes possible an explication of seeking the truth which clearly contrasts with other methods of "fixing belief", such as refusing to consider contrary evidence (the Method of Tenacity), accepting an institution's dictates (the Method of Authority), or the most coherent and/or elegant-seeming belief-set (the $A$ Priori Method). These three methods contrast with the Method of Science which communally seeks to conform beliefs to that which is independent of them, and has as its key enabling hypothesis that, "there are real things, whose characters are entirely independent of our opinions about them...and any man, if he have sufficient experience and he reason enough about it, will be led to the one True conclusion" (5.384).

However, just as when working out $\pi$ we may continue adding decimal places indefinitely and never finish our calculation, although we are continually drawing closer to $\pi$, so when we inquire we never reach a point where we have the entire truth and inquiry may cease. Given that we manage to get around the world without too many nasty surprises, we can assume that with respect to many of our beliefs we have reached the truth (8.43). However, we can never be absolutely sure which of our beliefs are the true ones. This is Peirce's commitment to fallibilism, which "requires a man to be at all times ready to dump his whole cart-load of beliefs, the moment experience is against them" (1.55). It is thus crucial to address an ambiguity in the famous phrase, "end of inquiry". It is 
not 'end' in the sense of 'finish'. It is 'end' in the teleological sense of 'aim' or 'goal'. Rather than a description of some future time where all questions are settled, Peirce's explication of truth is an idealised continuation of what scientists are doing now, namely settling questions about which they genuinely doubt. For this reason Russell's attempt to refute Peirce by arguing that since "the last man on earth", "will presumably be entirely occupied in keeping warm and getting nourishment, it is doubtful whether his opinions will be any wiser than ours" ("Dewey's New Logic" 145) is revealed as facilely missing the mark.

Although such idealisations might seem prima facie to philosophers such as Russell to be unscientific daydreams, yet they are one of science's most useful tools. For example, using the idealised notion of a frictionless plane, early modern scientists formulated laws of motion for horizontally moving objects with a conciseness and power not possible if they had factored in the frictions to which every moving object is subject. Thus, Peirce further explicates truth as follows:

Truth is a character which attaches to an abstract proposition, such as a person might utter. It essentially depends upon that proposition's not professing to be exactly true. But we hope that in the progress of science its error will indefinitely diminish, just as the error of 3.14159 , the value given for $\pi$, will indefinitely diminish as the calculation is carried to more and more places of decimals. What we call $\pi$ is an ideal limit to which no numerical expression can be perfectly true (5.565).

Such a view of truth - as something we must acknowledge that we necessarily fall short of gave rise to a further famously incredulous remark of Russell's that "this would enthrone Epimenides as the only sage" ("Dewey's New Logic" 145). However Peirce is merely claiming that insofar as we seek the truth we become part of a 'truth-seeking entity' (the community of inquiry) which is indefinitely large, although as individual inquirers we have finite epistemic powers.

\subsection{The Limit Concept of Truth: neither "Ontological" nor "Semantic"}

A distinction between "ontological" and "semantic" accounts is today often thought to partition philosophical approaches to truth. Ontological accounts understand the explication of truth to be a metaphysical problem and often speak of truth-makers. (See for instance, Fox, "Truthmaker", Armstrong, $A$ World of States of Affairs). A truthmaker for a true statement $p$ (e.g. "Snow is white") is defined as something the very existence of which entails $p$ (e.g. white snow). A notable problem for such views has been identifying truthmakers for true statements relevantly unlike "Snow is white", such as universal, negative and modal statements.

A natural enemy of truthmaker theories is deflationary, disquotational (Horwich, Truth) or prosententialist (Grover et al, A Prosentential Theory of Truth) accounts, which claim that 
everything there is to be said about truth is captured in formulae of the form: "p" is true iff $p .^{2}$ Such theories are often called "semantic" because they seem to claim that truth is merely a feature of our language: strictly, a particular relationship between object- and meta-language, following Tarski ("The Semantic Conception of Truth"3) Where truthmaker theorists treat truth as one among many 'real properties', deflationists often deny that truth is a property at all, for in stating ' $p$ is true' it appears that we are stating nothing over and above $p$. The supreme uninformativeness of this view has also been felt to be unsatisfying (Sellars, "Truth and 'Correspondence"').

One might think that the truth-theorist is forced to choose between ontological and semantic accounts. Ontological posits or no ontological posits - does this not partition logical space? But the practice-based nature of Peirce's theory of meaning, and its teleological explication of concepts, breaks up this dichotomy. If we hold a belief $p$ to be true, Peirce can say more about what this means than merely: $p$, whilst not needing to say that something exists, the very existence of which entails $p$. Rather, our holding $\mathrm{p}$ to be true means that we expect that future inquiry will converge on $p$.

Having explicated Peirce's pragmatist understanding of the meaning of truth, I will now proceed to consider three lines of objection to it.

\section{Is The Limit Concept of Truth Incoherent?}

It has been charged that Peirce's use of the limit concept to explicate truth is incoherent. I will consider three main approaches to this objection. Firstly, some have seemed to suggest that the very inclusion of infinite concepts vitiates Peirce's view. Thus Rorty complains, "there can be no such thing as an 'ideal audience' before whom justification would be sufficient to ensure truth, any more than there can be a largest integer" ("Is Truth a Goal of Enquiry?" 283).

Once again this fails to appreciate the true meaning of 'end of inquiry' as not a perfect epistemic resting place so much as precisely the model which ensures that inquiry might continue indefinitely. Moreover, consider the way in which integral calculus determines the area under a curve as an infinite sum of rectangles of infinitesimal width which - through the genius of mathematical methods discovered in the $17^{\text {th }}$ century - resolves to a finite, determinate quantity. This shows that it is not logically inconsistent to posit an infinite calculation yielding a finite,

\footnotetext{
${ }^{2}$ The 'minimalism' of Wright (Truth and Objectivity) is related to these views, but more complicated insofar as he attempts to construct truth as a 'minimal' norm of inquiry - an attempt which is criticised by Rorty in 1995. ${ }^{3}$ It should be noted that Tarski did not see himself as putting forward a theory of truth so much as conditions of adequacy for any theory.
} 
determinate answer. Although few now believe that Bishop Berkeley's outraged critique of the calculus for logical inconsistency ${ }^{4}$ should be taken seriously, the profound challenge it offers to traditional understandings of 'what is logical' - and the resources it offers for reconceiving the same - are still arguably insufficiently appreciated by philosophers whose minds generally dwell in more finite realms.

Secondly, Johnston has suggested that Peirce's account of truth is invalidated by Goedel's Incompleteness Theorem. He claims that at the limit of inquiry must lie an 'ideal theory' (T) which must be a set of sentences from which every true sentence may be deduced. He then objects that, "[a]s a matter of simple metalogic it could not be true that something is true if and only if it follows from the ideal theory T", for if $\mathrm{T}$ is rich enough to express arithmetic it will be rich enough for a Goedel argument to be constructed within it, so that there will be truths expressible but not provable within T (“Objectivity Refigured” 89).

However, is Peirce committed to every true statement being provable within the final opinion? Or merely included in it, somehow? It might be protested that Peirce has committed to every question receiving an answer at some point in time, so must be committed to one set of sentences which would collect all those answers together. However there is a serious logical fallacy here, resting on quantifier scope ambiguity. The pragmatist may commit to any question receiving an answer at some time, while not committing to there being any time at which every question has received an answer, just as the fact that everyone has a loving mother does not entail that there is some mother who loves everyone (Peirce 1.405, discussed in detail in Legg, "Argument-Forms which Turn Invalid Over Infinite Domains"). A similar point is made by Hookway (The Pragmatic Maxim, chapter 3) who distinguishes “...anyone who enquires 'into the nature of reality'...is fated to believe" some proposition, and "...anyone who investigates some question to which that proposition provides the answer is fated to believe" it.

Finally, Quine famously objected that approximation to a limit “depends on that of 'nearer than', which is defined for numbers and not for theories" ( Word and Object 23). Almeder has countered that for Peirce truth does not consist in indefinite approximation of a theory to an ultimate true theory, but in indefinite approximation of the probability that a proposition is correct to 1 (The Philosophy of Charles S. Peirce 49-80). Misak has conceded to Quine that "[i]nquiry can go very

\footnotetext{
${ }^{4}$ Berkeley, "The Analyst Or a Discourse Addressed to an Infidel Mathematician. Wherein it is Examined Whether the Object, Principles, and Inferences of the Modern Analysis Are More Distinctly Conceived, or More Evidently Deduced, than Religious Mysteries and Points of Faith. 'First Cast the Beam Out of Thine Own Eye; and Then Shalt Thou see Clearly to Cast out the Mote Out of Thy Brother's Eye'”.
} 
wrong for generations and so a given point in inquiry is not a point in a convergent process", claiming that all Peirce requires is that inquiry produce "consensus" (Truth and the End of Inquiry 123). However this seems to ride roughshod over certain key passages (such as 1.485 and 5.565 cited above. See also 7.110.). But even if our approach to the truth is not a steady, gradual improvement, it is arguable that the limit concept does pragmatic work in other respects. For example, it signifies that as the community of inquiry acquires truth, its self-correction becomes ever finer with regard to any given question, just as the continued working out of $\pi$ produces ever more decimal places. Any given theory begins with vague concepts with new and striking predictive power and gradually precisifies them until diminishing predictive returns lead scientists to other more exciting inquiries. This application of the limit idea, then, produces an idea of inquiry over and above a mere 'gathering of truths', like apples from a tree.

A further use for the limit concept is the idea of limit as constraint.

....as to the inkstand being on my table, though I should succeed in persuading myself and all who have seen it that it is a mere optical illusion, yet there will be a limit to this, and by the photographic camera, the balance, new witnesses, etc., it will, at last, I guess, force its recognition upon the world (8.153).

One is "limited" by something that restricts one's freedom in some way. The truth affects us no matter how we try to avoid it. In fact it affects us exactly insofar as we seek to avoid it, and moreover (Peirce argues) it eventually forces us to recognise it anyway. Hence Peirce's talk of fate or destiny with respect to truth:

This activity of thought by which we are carried...to a fore-ordained goal, is like the operation of destiny. No modification of the point of view taken, no selection of other facts for study, no natural bent of mind even, can enable a man to escape the predestinate opinion (5.407)

Hookway, however, has recently argued that later in life Peirce consciously shifted away from viewing truth as 'fated', and towards viewing it as a 'regulative hope' (The Pragmatic Maxim, Chapter 3, more on this below in $\S 4$ ).

Skagestad concedes to Quine only that the idea is vague, not meaningless. He then argues that vagueness is its great strength, for it can admit of a clear, quantitative interpretation in more mature sciences (e.g. those sufficiently developed for statistical methods to be applied to the measurement of quantities such as the speed of light) while retaining useful indeterminacy in less developed sciences. In the former, Bernoulli's Theorem means that enlarging measurement sample size enables scientists to bring the probability that the value of the quantity will be within any arbitrarily chosen margin of error arbitrarily close to 1 ("Peirce's Conception of Truth: A Framework for Naturalistic 
Epistemology?" 85). Note that, contra Almeder, these scientists are not claiming to be bringing the probability closer and closer to 1 that any particular statement about the speed of light is true. Rather, they chart an inter-relationship between three quantities: sample-size, margin of error, and the probability that a measurement falls within the margin.

One might add a further reply to Quine's objection which draws on the Pragmatic Maxim, as follows. Peirce does accept that it is difficult to gain any pragmatic grasp on the notion of the absolute nearness of a theory to the truth. How is such a quantity to be measured, and in what units? The notion would also seem to defeat pragmatism's third level of clarity since it would require us to compare our current best theory and things-in-themselves which we cannot experience directly. However, the notion of a theory being nearer to the truth than one's present theory is something scientists work with on a regular basis. If two theories are identical except that the former contains a new hypothesis which successfully predicts something that the latter does not, it would seem that the former is nearer to the truth. Therefore, by the Pragmatic Maxim, since the idea of 'nearer to the truth' translates into a projectible (if highly general) pattern of expectations with respect to relative predictive power, it is meaningful. Thus, although it is impossible for anyone to step outside the 'continuous' process of inquiry and make judgements about the veridicality tout court of any theory, by using relative judgements the community of inquiry may inch, generation by generation, ever closer to the truth.

It might be objected that the new hypothesis which makes new true predictions may also make many false predictions. Yet what is lost pragmatically by saying that the amended theory, despite its false predictions, is not nearer to the truth? It might be argued that a new hypothesis is nearer to the truth than its rivals only if it makes more true new predictions than false new predictions. However, this would seem to require that propositions be counted so that such ratios might be calculated. Peirce suggests that this makes no sense (e.g. at 7.216 he states, “'Predictions are not units; for they may be more or less detailed...”).

Consider the Copernican hypothesis that the Earth revolves around the sun. Against the background science of the day it made many false predictions - for instance, that Mercury and Venus should change size appreciably during the year. Nevertheless it was accepted by a growing number of scientists in the 1500s, despite its false predictions, because the true predictions it did make were so novel and suggestive. Eventually the false predictions were removed thanks to futher advances by Galileo and Kepler. Genuinely new true predictions are a major scientific achievement. Scientists who make them obviously have some greater understanding, and can only trust that any 
false predictions their new hypothesis makes will be resolved by future inquiry. To embrace Peirce's view of truth is just to say that we cannot diverge from the truth indefinitely whilst continuing to increase in predictive power. Thus the concept of one hypothesis being nearer to the truth than another can be spelled out in terms of the (pragmatically clear) concept of new predictive power, rather than in terms of the (pragmatically unclear) concept of making more true than false predictions.

I will now consider two objections to Peirce's limit concept of truth: one from pragmatistinclined philosophers that it is unjustifiably realist and, ironically, another from metaphysical realists that it is insufficiently mind-independent to call itself a realism at all.

\section{Peirce's Limit Concept Too Realist}

\subsection{Convergence?}

We have seen that Peirce's account of truth assumes that if inquiry proceeds long enough our belief will converge on a single answer to any given question. Many have wondered: what is the status of this assumption? What reason do we have to believe it? Thus Russell asked:

Is this an empirical generalization from the history of research? Or is it an optimistic belief in the perfectibility of man? Does it contain any element of prophecy, or is it a merely hypothetical statement of what would happen if men of science grew continually cleverer?

and concluded, "Whatever interpretation we adopt, we seem committed to some very rash assertion." ("Dewey's New Logic" 146). Rorty has also been a significant critic here (e.g. Consequences of Pragmatism, 130, "Is Truth a Goal of Enquiry?" 298), suggesting that consistent pragmatists should restrict themselves to trying to gain beliefs that are maximally well-justified, or agreed on by their current peers (exemplifying "solidarity"). Rorty notes that the further question of whether such beliefs are true is placed beyond any possible experience precisely by the idealization in the infinite long run across which Peirce defines truth, so that a belief may be believed by everyone over any length of time, but still be overturned at some time in the future. Thus, truth is not a goal of inquiry ("Is Truth a Goal of Enquiry?" 287. See also "Universality and Truth” 2.).

Even if inquiry produces convergence in belief, why should it be to one, single end-state? That Peirce's account by definition forbids what might be called pluralistic convergence has been viewed as regrettably closed-minded. The charge has been pursued on a number of fronts: Quine in terms of his favoured ontological relativity: (“...we have no reason to suppose that man's surface irritations even unto eternity admit of any one systematization that is scientifically better or simpler than all 
possible others" ( Word and Object 23), Hartry Field by imagining alien predication ("Realism and Relativism" 554), while Rorty presses the charge in terms of human cultural sensitivity (Contingency Irony and Solidarity). Rorty also goes so far as to suggest that even within Western epistemology the concept of truth is functionally heterogeneous ("Is Truth a Goal of Enquiry?" 286).

Here once again it is important to clarify, with the help of the Pragmatic Maxim, what the limit concept of truth actually means. As noted in 5.384 (cited above), it is a hypothesis that makes other hypotheses possible. Peirce's fallibilism does ensure that the hypothesis has no specific consequences in the sense it does not provide warrant for any specific belief about the world. But that does not mean that it has no meaning. Peircean pragmatism sidesteps the demands of the deductivist epistemologist by making possible a future-directed justification, which draws on the Biblical maxim, "By their fruits shall ye know them". In other words, he suggests that inquirers who believe their efforts will converge on a single answer to any question they pursue rigorously are more likely to make progress in finding out whatever truth there happens to be.

Relatedly, and in terms that betray Peirce's lifelong debt to Kant, the hypothesis of convergence on a single answer to any question can be viewed as a regulative hope. Late in his career (1908) Peirce wrote in a letter to Lady Welby, "I do not say that it is infallibly true that there is any belief to which a person would come if he were to carry his inquiries far enough. I only say that that alone is what I call Truth" (cited Haack, "The Pragmatist Theory of Truth" 246).

This last quote also highlights the way in which Peirce's account embodies a transcendental argument. We human beings are thrown into a diverse, often surprising, sometimes dangerous world and in order to navigate it must fix our beliefs somehow, so that we may act upon them. Inquiry is one (though, Peirce notes, not the only) means of fixing belief. Without the hypothesis that inquiry will provide an answer to our questions we can make little sense of inquiring at all, and Peirce submits that careful analysis of "providing an answer", shows that convergence on shared belief is presupposed by it (more on this in Hookway, The Pragmatic Maxim Chapters 2 and 3).

\section{Peirce's Limit Concept Insufficiently Realist}

On the other hand, many self-identified realists have been dissatisfied with the way Peirce explicates truth as internal to inquiry (a move Putnam famously called 'internal realism'). Horwich sums up these objections by claiming, "truth has a certain purity" (Truth, 12. Misak traces this complaint against pragmatism back to Paul Carus in 1911 in "“Pragmatism on Solidarity, Bullshit, and other Deformities of Truth"). If the truth is independent of what anyone might think it to be, 
as Peirce himself claims, shouldn't it be kept free of 'epistemic' notions such as belief, and agreement within the community of inquiry, since surely these things can come apart from truth in principle?

\subsection{Lost Facts}

Often cited as a clear illustration of how truth and agreement within the community of inquiry can come apart is facts about the past. Surely there are some past events which all future improvements in our knowledge might leave us ignorant of? Smart offers, " $t$ that Winston Churchill sneezed twice more on a certain date in 1941 than did Franklin Roosevelt" ("Realism v. Idealism” 302), Johnston, "the number of cakes on a particular tray at a specific time during a party held years ago" ("Objectivity Refigured" 91) and Field the number of dinosaurs that ever existed ("Realism and Relativism" 556). Mustn't Peirce say that there is no truth about these matters? And isn't this absurd? (For further discussion, see Hookway, Peirce 241, Howat, ““Regulative Assumptions”.)

However, a weakness of these arguments is their confident claim that no inquiry will settle such matters. How can we be sure of this? Peirce urges a greater fallibilism:

...it is unphilosophical to suppose that, with regard to any given question (which has any clear meaning), investigation would not bring forth a solution of it, if it were carried far enough... Who can be sure of what we shall not know in a few hundred years (5.409)?

Smart maintains that he does know enough ("largely from science") to know that it would never be possible to decide the question of Churchill's sneezes ("Realism v. Idealism" 303). However Peirce gives the amusing example of Comte, who when asked for a clear example of something scientifically undiscoverable cited the chemical composition of stars, but, “...the ink was scarcely dry upon the printed page before the spectroscope was discovered and that which he had deemed absolutely unknowable was well on the way of getting ascertained" (1.138). To state categorically that certain facts cannot ever be discovered is much worse, Peirce urges, than cherishing a foolish hope that any given fact can be. For:

...there is no positive sin against logic in trying any theory which may come into our heads, so long as it is adopted in such a sense as to permit the investigation to go on unimpeded and undiscouraged. On the other hand, to set up a philosophy which barricades the road of further advance toward the truth is the one unpardonable offence in reasoning....(1.136)

Such sunny epistemic optimism naturally goads sceptical philosophers to frame hypotheses involving more inaccessible entities - either undetected by historical accident or undetectable in principle. Surely such entities are not logically impossible? Thus Johnston defines Enigmas as "entities essentially indetectable by us", and argues: "It cannot be settled a priori whether there are or are not Enigmas. But if there were...no good theory would say there were" ("Objectivity 
Refigured" 96-7). However this move now falls foul of the Pragmatic Maxim. What experiencable effects does this hypothesis lead us to expect? Absolutely nothing, by definition. Thus, Enigmas are meaningless.

Peirce's realism does not understand real entities to be entirely disconnected from people's minds (which would be rather counterproductive, after all, if we wish to know about them). It draws rather on the infinity of the community of inquiry: "reality is independent, not necessarily of thought in general, but only of what you or I or any finite number of [persons] may think about it..." (5.408). In other words, agreement amongst inquirers constitutes truth but agreement amongst no cardinality of inquirers guarantees truth. Rather, the community of inquiry always in principle retains the potential for further discovery of error. This epistemic continuity "is the idea of fallibilism objectified" (1.171).

Peirce's limit concept of truth skates an exceedingly - arguably infinitely - delicate line between a number of categories which philosophers generally like to oppose: pragmatism and metaphysical realism, internalism and externalism, semantics and ontology. However as with the mathematical calculus, in its apparent paradox arguably lies its power. Consistently with its teachings, its true justification (or otherwise) will lie in whatever use philosophers do in fact make of it in future inquiry.

\section{BIO}

Catherine Legg holds a BA (hons) from University of Melbourne, an MA in Philosophy from Monash University and a PhD from Australian National University, where her thesis ("Modes of Being”) concerned Charles Peirce's philosophical categories. After a spell of hands-on ontological engineering in the early years of this century she returned to academia and now teaches at University of Waikato in New Zealand. Her current research bridges philosophy of language, logic, ontology and AI, with a side interest in 'cat metaphysics'.

\section{WORKS CITED}

Almeder, R.: The Philosophy of Charles S. Peirce: A Critical Introduction. Oxford: Blackwell (1980) Armstrong, D.M.: A World of States of Affairs. Cambridge: Cambridge University Press (1997) Field, H.: "Realism and Relativism." Journal of Philosophy. (Oct, 1982), 79 (10): 553-567. Forster, P.: Peirce and the Threat of Nominalism. New York: Cambridge University Press (2011) Fox, J.: “Truthmaker.” Australasian Journal of Philosophy. (June, 1987), 65 (2): 188-207 Grover, D., Camp, J.L., Belnap, N.: A Prosentential Theory of Truth. New Jersey: Princeton University Press (1992) 
Haack, S.: "The Pragmatist Theory of Truth." The British Journal for the Philosophy of Science.

(Sep., 1976), 27 (3): 231-249

Hookway, C: Peirce. London: Routledge (1985)

Hookway, C.: Truth, Rationality and Pragmatism: Themes from Peirce. Oxford: Clarendon Press (2002)

Hookway, C.: The Pragmatic Maxim: Essays on Peirce and Pragmatism. Oxford: Oxford University Press (2012)

Horwich, P.: Truth. Oxford: Basil Blackwell (1990)

Howat, A.: "Regulative Assumptions, Hinge Propositions and the Peircean Conception of Truth." Erkenntnis (2013) 78: 451-468

James, W.: Pragmatism. London: Longman's Green (Meridian Edition) (1907)

Johnston, M.: "Objectivity Refigured: Pragmatism Without Verificationism", J. Haldane and C. Wright, ed.s, Reality, Representation and Projection. Oxford: Oxford University Press, 85-130 (1993)

Legg, C.: “Argument-Forms which Turn Invalid Over Infinite Domains: Physicalism as Supertask?” Contemporary Pragmatism (2008), 5(1): 1-11

Misak, C.: Truth and the End of Inquiry: A Peircean Account of Truth. Oxford: Oxford University Press (2001, expanded edition: 2004)

Misak, C. (2007), ed.: The New Pragmatists. Oxford: Oxford University Press (2007).

Misak, C.: "Pragmatism on Solidarity, Bullshit, and other Deformities of Truth." Midwest Studies in Philosophy (2008), 32 (1): 111-121

Peirce, C. S.: Collected Papers, vol. 1-7 ed. C. Hartshorne and P. Weiss. Vol 8 ed. A. Burks. Cambridge, Mass.: Harvard University Press (1931-1958)

Quine, W.V.O. Word and Object. New York: MIT Press (1960)

Rorty, R.: Consequences of Pragmatism. Minneapolis: University of Minnesota Press (1982)

Rorty, R.: Contingency, Irony, and Solidarity. Cambridge: Cambridge University Press (1989)

Rorty, R.: "Is Truth a Goal of Inquiry? Davidson vs. Wright." The Philosophical Quarterly. (July 1995), 45 (180): 281-300

Rorty, R.: "Universality and Truth", in R. Brandom, ed., Rorty and his Critics. Oxford: Oxford University Press (2000)

Russell, B.: "Dewey's New Logic", in P.A. Schilpp, ed., The Philosophy of John Dewey, Library of Living Philosophers. Evanston, IL: Northwestern University Press (1939): 135-156

Sellars, W.: “Truth and 'Correspondence'.” Journal of Philosophy. (Jan 1962), 59 (2): 29-56

Skagestad, P.: "Pragmatic Realism: The Peircean Argument Reexamined", Review of Metaphysics (1980), 33 (3): 527-540

Skagestad, P.: The Road of Inquiry. New York: Columbia University Press (1981)

Skagestad, P.: "Peirce's Conception of Truth: A Framework for Naturalistic Epistemology?" Naturalistic Epistemology, ed. A. Shimony and D. Nails. Dordrecht: Reidel (1987): 73-90

Smart, J.J.C.: "Realism v. Idealism." Philosophy (1986) 61 (237): 295-312

Tarski, A.: "The Semantic Conception of Truth and the Foundations of Semantics." Philosophy and Phenomenological Research (1944), 4: 341-376 
Wiggins, D.: "Reflections on Inquiry and Truth Arising from Peirce's Method for the Fixation of Belief”, in C. Misak, ed., Cambridge Companion to Peirce (2004): 87-126.

Wright, C.J.G: Truth and Objectivity. Cambridge MA: Harvard University Press (1992).

BIBLIO 640 words 